\title{
Effect of disinfection techniques on physical-mechanical properties of a microwave-activated acrylic resin
}

\author{
Carmen Beatriz Borges Fortes ${ }^{1}$, Fabrício Mezzomo Collares ${ }^{1 *}$, Vicente Castelo Branco Leitune ${ }^{1}$, \\ Priscila Raquel Schiroky ${ }^{1}$, Stéfani Becker Rodrigues ${ }^{1}$, Susana Maria Werner Samuel, \\ Cesar Liberato Petzhold ${ }^{2}$ and Valter Stefani ${ }^{2}$
}

\author{
${ }^{1}$ Laboratório de Materiais Dentários - LAMAD, Departamento de Odontologia \\ Conservadora - DOC, Faculdade de Odontologia, Universidade Federal do Rio Grande do SuI - UFRGS, \\ Porto Alegre, RS, Brasil \\ ${ }^{2}$ Departamento de Química Orgânica - DQO, Instituto de Química, \\ Universidade Federal do Rio Grande do Sul - UFRGS, Porto Alegre, RS, Brasil \\ *fabricio.collares@ufrgs.br
}

\begin{abstract}
The effects of disinfection by microwave irradiation and immersion in peracetic acid on the physical-mechanical properties of a microwave-activated acrylic resin were evaluated. Specimens of acrylic resin were divided into a control group (specimens not disinfected) and 2 test groups subjected to one disinfection method: microwave irradiation at $850 \mathrm{~W}$ for 1 minute or immersion in $50 \mathrm{~mL}$ of $0.2 \%$ peracetic acid for 5 minutes. Specimens were submitted to Knoop hardness, flexural strength, flexural modulus, Izod impact, water sorption and solubility, glass transition temperature, and degree of conversion tests. Microwave disinfection significantly increased the mean Knoop hardness, Izod impact strength, water sorption, water solubility and glass transition temperature, whereas the flexural properties remained unaffected. Microwave disinfection increased the degree of conversion. Peracetic acid disinfection showed no changes in any properties. Both disinfection techniques did not adversely affect the evaluated properties.
\end{abstract}

Keywords: acrylic resins, microwave disinfection, peracetic acid.

\section{Introduction}

Complete dentures are colonized and infected by microorganisms, forming a denture biofilm and leading to oral fungal infection. Candida albicans is commonly found in the oral cavity at denture base, changing the oral environment by increasing part of the oral microflora ${ }^{[1]}$. The presence of Candida albicans in denture biofilm is a major factor in the multifactorial etiology of denture-related stomatitis, a common opportunistic infection found in denture wearers ${ }^{[2,3]}$.

Poor denture hygiene is associated with denture-related stomatitis, as it could lead to fast establishment of a biofilm ${ }^{[4,5]}$. This biofilm could be removed by mechanical methods (brushing or ultrasound), chemical methods (soaking in chemicals), using a microwave oven or an association of different methods ${ }^{[6]}$. However, a mechanical biofilm removal requires a degree of manual dexterity that is often lacking among older people ${ }^{[5]}$. In addition, complete dentures contaminated by Candida albicans are a potential source of infection and re-infection of the oral soft tissues, and its disinfection has been recommended as an adjuvant in the treatment of stomatitis and as an essential procedure for maintaining a healthy oral mucosa ${ }^{[7,8]}$. Many protocols for denture disinfection have been proposed, including immersion in chemical solutions such as glutaraldehyde ${ }^{[9]}$, sodium perborate ${ }^{[10]}$, sodium hypochlorite ${ }^{[11,12]}$, chlorhexidine digluconate ${ }^{[7]}$, peracetic acid $^{[11,12]}$, and microwave irradiation ${ }^{[7,13]}$. Ideally, the choice of the disinfectant method should be made with regard to its effectiveness in inactivating microorganisms without detrimental effects on the acrylic resins.

Originally used to polymerize microwave-activated acrylic resins ${ }^{[14,15]}$, microwave irradiation has been used for post-polymerization treatment ${ }^{[16]}$ and has been shown to disinfect effectively ${ }^{[7,17,18]}$. Different time (3, 5, and 6 minutes) and power $(650$ and $720 \mathrm{~W})$ settings of microwave irradiation have been proposed in the literature for denture disinfection ${ }^{[10,19-22]}$. Despite its effectiveness in disinfection, these protocols have reached contradictory findings, including deleterious effects on some physical and mechanical properties due to the material heating during the irradiation, which could affect the polymer structure ${ }^{[19-21]}$. Previous studies suggested that the time the acrylic resins are subjected to heat during disinfection could be reduced in order to produce adequate disinfection without any adverse effects ${ }^{[7,23,24]}$. Microwave exposure time of 1 minute has been found to be effective for disinfection against Candida albicans ${ }^{[17,18]}$. However, only the effects on the hardness and flexural strength were verified with 1 minute of microwave irradiation exposure at high power ${ }^{[22]}$.

Peracetic acid $\left(\mathrm{C}_{2} \mathrm{H}_{4} \mathrm{O}_{3}\right)$ has been suggested to be used for acrylic resins disinfection ${ }^{[11,12,25]}$, acting even at low concentrations with a broad antimicrobial spectrum and producing no harmful by products ${ }^{[25,26]}$. The disinfection efficacy of immersion in $0.2 \%$ peracetic acid-based disinfectant has been shown in the literature, including against 
Candida albicans ${ }^{[17,25]}$. Likewise, immersion in a chemical solution may cause water sorption and polymer solubility, altering the polymer structure ${ }^{[9]}$. Despite color stability and surface roughness, its effect on the physical-mechanical properties of microwave-activated denture base acrylic resins have not been evaluated ${ }^{[11,12]}$.

The aim of this study was to investigate the effects of two methods of disinfection, microwave irradiation at $840 \mathrm{~W}$ for 1 minute and immersion in $0.2 \%$ peracetic acid for 5 minutes, on the Knoop hardness, flexural strength, flexural modulus, Izod impact, water sorption and solubility, glass transition temperature, and degree of conversion of one type of microwave-activated denture base acrylic resin. The null hypothesis was that microwave irradiation and peracetic acid disinfection protocols would not detrimentally affect the properties of the material.

\section{Materials and Methods}

The material selected for this study was a microwave-activated denture base acrylic resin (powder: PMMA; liquid: MMA/EDMA) (VIPI WAVE; Dental VIPI Ltda., São Paulo, Brazil). Rectangular $(64.00 \times 10.00 \times 3.00 \pm 0.5 \mathrm{~mm})$ and disc-shaped $(50.00 \times 0.5 \pm 0.5 \mathrm{~mm})$ test specimens were produced in casts prepared by the investment of stainless steel casts in addition silicone, further supported by a type II dental die within the flask.

After dental die setting (2 hours), the acrylic resin was prepared with a powder-liquid ratio of $2: 1$ by weight. The monomer and then the powder were placed in a glass mixing vessel and hand mixed with a spatula until homogenization. When the plastic phase was reached, the acrylic resin was inserted into the casts.

The flask was packed and pressed with a $500 \mathrm{~kg}$ load and then instantly opened to remove the excess resin. Afterwards, it was kept under 1000-kg pressure for 30 minutes. The specimens were submitted to a microwave polymerization cycle at $140 \mathrm{~W}$ for 20 minutes plus 5 minutes at $420 \mathrm{~W}$. After polymerization and flask cooling for 4 hours, the specimens were removed and any excess was trimmed with a tungsten bur and an aluminum oxide stone bur, as well as polished with progressively finer grades $(280,400,600,1000)$ of silicon carbide sandpapers.

The accuracy of the specimens' dimensions was verified with a digital caliper. The final polishing was reached by using a polishing machine, pumice, and calcium carbonate, resulting in a smooth and bright surface. The rectangular and disc-shaped specimens were randomly divided into one control group and two experimental groups. In the control group (CG), the specimens were not disinfected. The specimens from the microwave group (MW) were immersed in $50 \mathrm{~mL}$ of deionized water and irradiated at $840 \mathrm{~W}$ for 1 minute in a microwave oven (MB-315 Ml Intellowave; LG Electronics, Manaus, Brazil) to simulate the disinfection. The specimens from the peracetic acid group (PA) were immersed in $50 \mathrm{~mL}$ of $0.2 \%$ peracetic acid (Sterilife; Lifemed Produtos Médicos Comércio Ltda., São Paulo, Brazil) for 5 minutes to simulate the disinfection.

\subsection{Knoop hardness}

Knoop hardness was measured by using a microhardness tester (MICROMET; Bueller, Dusseldorf, Germany). Indentations were made under a 25 -g load for 10 seconds. Five indentations were made on each disc-shaped specimen $(n=5)$, one in the center and four $100 \mu \mathrm{m}$ from the center. The average of the five indentations was considered to be the specimen's hardness.

\subsection{Flexural strength and flexural modulus}

The flexural strength and flexural modulus were tested according to ISO $1567^{[27]}$. The rectangular specimens $(\mathrm{n}=10)$ were stored in distilled water at $37^{\circ} \mathrm{C}$ for $50 \pm 2$ hours. The three-point bending test was performed with an increasing load from $0 \mathrm{~N}$, at a crosshead speed of $5 \mathrm{~mm} / \mathrm{min}( \pm 1 \mathrm{~mm} / \mathrm{min})$.

\section{3 lzod impact strength}

Thirty rectangular specimens $(n=10)$ were submitted to an impact strength test in the Izod configuration, according to the specifications of ASTM D256 - Izod impact modified, because the specimens were not notched ${ }^{[28]}$. An impact tester (EMIC AIC-1; Equipamentos e Sistemas de Ensaio Ltda., São José dos Pinhais, Brazil) was used to measure the impact energy required to fracture the specimens.

\subsection{Water sorption and solubility}

Fifteen disc-shaped specimens $(n=5)$ were used to determine the water sorption and solubility according to the method described in ISO $1567^{[27]}$. Disc-shaped specimens were conditioned to a constant mass in a desiccator placed in an oven at $37^{\circ} \mathrm{C}$ for 24 hours. The specimens were weighed and reweighed until the weight loss was not greater than $0.0002 \mathrm{~g}$ in any 24 -hour period. They were immersed in $50 \mathrm{~mL}$ of deionized water at $37^{\circ} \mathrm{C}$ for 7 days. Afterwards, the specimens were removed from the water, dried with a paper towel, weighed, and reconditioned to a constant mass in the desiccator.

\subsection{Glass transition temperature $(\mathrm{Tg})$}

The glass transition temperature was assessed by using the differential scanning calorimetry (DSC) method with a calorimeter (DSC-4; Perkin Elmer, Beaconsfield, England). The specimens $(n=3)$, weighing approximately $10 \mathrm{mg}$, were contained in aluminum pans and subjected to a temperature range of $50{ }^{\circ} \mathrm{C}$ to $90^{\circ} \mathrm{C}$ at a heating rate of $10^{\circ} \mathrm{C}$ or $20^{\circ} \mathrm{C}$ per minute. The glass transition temperature was determined in the second heating cycle.

\subsection{Degree of Conversion (DC)}

The degree of conversion was measured by micro-Raman spectroscopy, one specimen of each group was used $(n=1)$. The spectrum peaks of the double bonds between the unreacted carbon atoms $(\mathrm{C}=\mathrm{C})$ around $1650 \mathrm{~cm}^{-1}$ and the $\mathrm{C}=\mathrm{O}$ bonds around $1750 \mathrm{~cm}^{-1}$ were analyzed. The percentage of double bonds was determined based on the peak areas in the monomer and polymer spectra. 
Table 1. Mean and standard deviation values of evaluated properties in control, microwave (MW) and peracetic acid (PA) groups.

\begin{tabular}{lcccrc}
\hline \multicolumn{1}{c}{ Properties } & Control & MW & PA & F & \multicolumn{1}{c}{ P } \\
\hline Knoop hardness $(\mathrm{KHN})$ & $21 \pm 1^{\mathrm{b}}$ & $24 \pm 1^{\mathrm{a}}$ & $21 \pm 1^{\mathrm{b}}$ & 15.000 & $<.001$ \\
Flexural strength $(\mathrm{MPa})$ & $93 \pm 10^{\mathrm{a}}$ & $93 \pm 10^{\mathrm{a}}$ & $96 \pm 11^{\mathrm{a}}$ & 0.28 & .758 \\
Flexural modulus $(\mathrm{MPa})$ & $2551 \pm 63^{\mathrm{a}}$ & $2555 \pm 68^{\mathrm{a}}$ & $2546 \pm 64^{\mathrm{a}}$ & 0.0481 & .953 \\
Izod impact strength $(\mathrm{J} / \mathrm{m})$ & $98 \pm 15^{\mathrm{b}}$ & $129 \pm 15^{\mathrm{a}}$ & $98 \pm 11^{\mathrm{b}}$ & 16.830 & $<.001$ \\
Water sorption $\left(\mu \mathrm{g} / \mathrm{mm}^{3}\right)$ & $25 \pm 2^{\mathrm{b}}$ & $8 \pm 1^{\mathrm{a}}$ & $25 \pm 2^{\mathrm{b}}$ & 160.556 & $<.001$ \\
Water solubility $\left(\mu \mathrm{g} / \mathrm{mm}^{3}\right)$ & $0.8 \pm 0.1^{\mathrm{b}}$ & $0.2 \pm 0.1^{\mathrm{a}}$ & $0.8 \pm 0.1^{\mathrm{b}}$ & 60.000 & $<.001$ \\
Glass transition temperature $\left({ }^{\mathrm{b}} \mathrm{C}\right)$ & $103 \pm 2^{\mathrm{b}}$ & $109 \pm 2^{\mathrm{a}}$ & $103 \pm 2^{\mathrm{b}}$ & 9.000 & .016 \\
\hline
\end{tabular}

Different letters in the same line denotes statistically significant difference (one-way ANOVA and Tukey test, $p<.05$ ). MW, microwave group; PA, peracetic acid group; $P$, p-value; F, Fisher-Snedecor distribution.

\subsection{Statistical analysis}

The normality of the data was evaluated using the Kolmogorov-Smirnov test. The data were statistically analyzed with one-way ANOVA and the Tukey post hoc test with $\alpha=0.05$ level of significance. Analyzes were performed on SigmaPlot 12.0 Software (Systat Software Inc., San Jose, USA).

\section{Results}

All data are reported on Table 1. The microwave group (MW) showed the highest values, differing significantly $(p<.05)$ from the control and peracetic acid (PA) groups for the following properties: Knoop hardness $(24 \pm 1 \mathrm{KHN})$, Izod impact strength $(129 \pm 15 \mathrm{~J} / \mathrm{m})$, water sorption $\left(8 \pm 1 \mu \mathrm{g} / \mathrm{mm}^{3}\right)$, water solubility $\left(0.2 \pm 0.1 \mu \mathrm{g} / \mathrm{mm}^{3}\right)$, and glass transition temperature $\left(109 \pm 2{ }^{\circ} \mathrm{C}\right)$. There was no significant difference between the control and peracetic acid (PA) groups. For flexural strength and flexural modulus, there were no significant differences among the 3 groups. The microwave group (MW) showed a degree of conversion of $92 \%$, versus $88 \%$ for the control group and $87 \%$ for the peracetic acid group (PA).

\section{Discussion}

This study examined the effects of microwave irradiation and peracetic acid disinfection protocols on a denture base acrylic resin activated by microwave energy. It is desirable for microwave and chemical disinfection to not affect any physical-mechanical properties of denture base resins. The null hypothesis that microwave irradiation and peracetic acid would not detrimentally affect the properties of the material was accepted. Knoop hardness, impact strength, water sorption, water solubility, glass transition temperature, and degree of conversion were improved by microwave irradiation, while the peracetic acid disinfection did not affect any of the properties. Also, all of the groups fulfilled the requirements regarding water sorption $\left(<32 \mathrm{mg} / \mathrm{mm}^{3}\right)$, water solubility $\left(<1.6 \mathrm{mg} / \mathrm{mm}^{3}\right)$, flexural strength $(>65 \mathrm{MPa})$, and flexural modulus ( $>2500 \mathrm{MPa})$, according to ISO $1567^{[27]}$.

The use of microwave irradiation exposure at high power during 1 minute was shown to be effective as a disinfection method for dentures with Candida albicans biofilm ${ }^{[17,18]}$, and three microwave irradiation cycles $(850 \mathrm{~W} / 1$ minute) were shown to completely sterilize the denture surface ${ }^{[7]}$. Previous studies have shown contradictory results about the effects of disinfection by microwave irradiation on properties of the acrylic resins. Microwave irradiation ( $650 \mathrm{~W} / 3$ minutes) was observed to decrease the Knoop hardness of acrylic $\operatorname{resin}^{[19]}$. In the present study, the Knoop hardness significantly increased after microwave polymerization, as did the Izod impact strength and glass transition temperature. Others suggested that the protocol $(720 \mathrm{~W} / 5$ minutes) reduced $^{[20]}$ or did not affect $(650 \mathrm{~W} / 3$ and 5 minutes $)$ the impact strength ${ }^{[19,23]}$. A protocol of $650 \mathrm{~W} / 3$ minutes decreased the glass transition temperature of acrylic resin ${ }^{[21]}$. In this study, the flexural strength and flexural modulus did not differ significantly in the microwave-disinfected specimens, compared with the control specimens. Previous studies $(650 \mathrm{~W} / 3$ minutes, $650 \mathrm{~W} / 1$ minute, and $650 \mathrm{~W} / 5$ minutes $)$ corroborate the flexural strength results ${ }^{[1,22,23]}$. With a protocol of $720 \mathrm{~W} / 5$ minutes, another study showed a decrease in the flexural modulus ${ }^{[20]}$. The water sorption and solubility of complete denture bases in a previous study $(650 \mathrm{~W} / 6$ minutes) showed no significant changes ${ }^{[13]}$. In the present study, both properties significantly decreased after microwave disinfection. Conflicts in the literature may be attributed to the differences in the disinfection time, power of the microwave oven, water volume and types of materials used, leading to contradictory conclusions concerning the safety of microwave disinfection ${ }^{[20,24]}$.

While the microwave irradiation lasted only 1 minute in the present investigation, most of the studies were conducted using at least 3 minutes of exposure and showed deleterious effects on physical-mechanical properties. This could explain the main differences in the results. Reduced microwave irradiation time did not cause adverse effects on acrylic resins, corroborating with preliminary studies ${ }^{[22,24]}$. During microwave irradiation, the amount of unreacted monomer reduces due to further polymerization ${ }^{[10,18]}$, and the residual monomer released into water increases ${ }^{[21,22]}$. The heating generated could increase the water sorption, inducing a plasticizing effect that may affect the material ${ }^{[13]}$, besides the plasticizing effect of residual monomers ${ }^{[14]}$. All of these mechanisms must be considered as factors that can change the physical-mechanical properties of the acrylic resins ${ }^{[21]}$.

It could be assumed that, in this study, further polymerization and release of residual monomer into water may have overcome the detrimental plasticizing effect of water uptake and residual monomers on polymeric chains. The increased degree of conversion for the microwave group (MW) reinforces this assumption, as the supposed lower residual monomer content after the further polymerization 
is the result of a higher degree of conversion ${ }^{[15]}$. In addition, a high degree of conversion results in increased glass transition temperature ${ }^{[21]}$.

The effect of $2 \%$ peracetic acid disinfection with 30 and 60 minutes of immersion on the color stability and surface roughness of acrylic resins was previously investigated and both properties were altered, but without clinical significance ${ }^{[11]}$. When a lower peracetic acid concentration (1\%) with 30 minutes of immersion was evaluated, it did not affect the surface roughness ${ }^{[12]}$. The acrylic resin surfaces roughness is an important property, as an increased roughness can promote attachment of microorganisms and the colonization of the surface ${ }^{[4]}$. In the present study, disinfection with $0.2 \%$ peracetic acid for 5 minutes did not affect the evaluated properties. Immersion in disinfectant solutions could affect the physical-mechanical properties due the sorption of the solution and its plasticizing effect into the polymer, and the detrimental effect appears to be time and concentration dependent ${ }^{[29]}$. The low concentration and the immersion time of only 5 minutes used in this study could explain the findings. Hence, the use of higher concentration or immersion time seems to be not justified, as the immersion in $0.2 \%$ peracetic acid-based disinfectant for 5 minutes has been found to be effective against Candida albicans ${ }^{[17]}$.

The results of this study suggest that the evaluated disinfectant protocols of microwave irradiation and immersion in peracetic acid are shown to be promising in disinfecting complete dentures. It is important to remember that the results may only partially predict the clinical performance of complete dentures. Other properties of acrylic resins should be investigated, such as dimensional stability. Additionally, further research evaluating the effects of cumulative disinfections should be performed.

\section{Conclusions}

Disinfection of acrylic resin by microwave irradiation exposure at high power $(850 \mathrm{~W})$ for 1 minute and immersion in $0.2 \%$ peracetic acid for 5 minutes cause no damage to the physical-mechanical properties of the microwave-activated denture base acrylic resin. These findings indicate that both protocols shown to be safe for disinfection of complete dentures maintaining the physical-mechanical properties of the acrylic resin.

\section{References}

1. Radford, D. R., Challacombe, S. J., \& Walter, J. D. (1999). Denture plaque and adherence of Candida albicans to denturebase materials in vivo and in vitro. Critical Reviews in Oral Biology and Medicine, 10(1), 99-116. http://dx.doi.org/10.11 77/10454411990100010501. PMid:10759429.

2. Barbeau, J., Seguin, J., Goulet, J. P., Koninck, L., Avon, S. L., Lalonde, B., Rompre, P., \& Deslauriers, N. (2003). Reassessing the presence of Candida albicans in denture-related stomatitis. Oral Surgery, Oral Medicine, Oral Pathology, Oral Radiology, and Endodontology, 95(1), 51-59. http://dx.doi.org/10.1067/ moe.2003.44. PMid:12539027.

3. Ramage, G., Tomsett, K., Wickes, B. L., Lopez-Ribot, J. L., \& Redding, S. W. (2004). Denture stomatitis: a role for Candida biofilms. Oral Surgery, Oral Medicine, Oral Pathology, Oral
Radiology, and Endodontology, 98(1), 53-59. http://dx.doi. org/10.1016/j.tripleo.2003.04.002. PMid:15243471.

4. Gendreau, L., \& Loewy, Z. G. (2011). Epidemiology and etiology of denture stomatitis. Journal of Prosthodontics, 20(4), 251-260. http://dx.doi.org/10.1111/j.1532-849X.2011.00698.x. PMid:21463383.

5. Kulak-Ozkan, Y., Kazazoglu, E., \& Arikan, A. (2002). Oral hygiene habits, denture cleanliness, presence of yeasts and stomatitis in elderly people. Journal of Oral Rehabilitation, 29(3), 300-304. http://dx.doi.org/10.1046/j.1365-2842.2002.00816.x. PMid:11896849.

6. de Souza, R. F., de Freitas Oliveira Paranhos, H., Lovato da Silva, C. H., Abu-Naba'a, L., Fedorowicz, Z., \& Gurgan, C. A. (2009). Interventions for cleaning dentures in adults. Cochrane Database of Systematic Reviews, 7(4), CD007395. http://dx.doi. org/10.1002/14651858.CD007395.pub2. PMid:19821412.

7. Banting, D. W., \& Hill, S. A. (2001). Microwave disinfection of dentures for the treatment of oral candidiasis. Special Care in Dentistry, 2l(1), 4-8. http://dx.doi.org/10.1111/j.1754-4505.2001. tb00216.x. PMid:11795452.

8. Garcia-Cuesta, C., Sarrion-Perez, M. G., \& Bagan, J. V. (2014). Current treatment of oral candidiasis: a literature review. Journal of Clinical and Experimental Dentistry, 6(5), e576-e582. http:// dx.doi.org/10.4317/jced.51798. PMid:25674329.

9. Schwindling, F. S., Rammelsberg, P., \& Stober, T. (2014). Effect of chemical disinfection on the surface roughness of hard denture base materials: a systematic literature review. The International Journal of Prosthodontics, 27(3), 215-225. http://dx.doi.org/10.11607/ijp.3759. PMid:24905261.

10. Machado, A. L., Breeding, L. C., Vergani, C. E., \& da Cruz Perez, L. E. (2009). Hardness and surface roughness of reline and denture base acrylic resins after repeated disinfection procedures. The Journal of Prosthetic Dentistry, 102(2), 115-122. http://dx.doi.org/10.1016/S0022-3913(09)60120-7. PMid:19643225.

11. Fernandes, F. H., Orsi, I. A., \& Villabona, C. A. (2013). Effects of the peracetic acid and sodium hypochlorite on the colour stability and surface roughness of the denture base acrylic resins polymerised by microwave and water bath methods. Gerodontology, 30(1), 18-25. http://dx.doi.org/10.1111/j.17412358.2012.00640.x. PMid:22486758.

12. Guiraldo, R. D., Sczepanski, F., Sczepanski, C. R. B., Berger, S. B., Consani, R. L. X., \& Gonini-Junior, A. (2014). Effect of sodium hypochlorite and peracetic acid on the surface roughness of acrylic resin polymerized by heated water for short and long cycles. European Journal of Dentistry, 8(4), 533-537. http:// dx.doi.org/10.4103/1305-7456.143638. PMid:25512737.

13. Seó, R. S., Vergani, C. E., Giampaolo, E. T., Pavarina, A. C., Reis, J. M. S. N., \& Machado, A. L. (2008). Effect of disinfection by microwave irradiation on the strength of intact and relined denture bases and the water sorption and solubility of denture base and reline materials. Journal of Applied Polymer Science, 107(1), 300-308. http://dx.doi.org/10.1002/app.27120.

14. Azzarri, M. J., Cortizo, M. S., \& Alessandrini, J. L. (2003). Effect of the curing conditions on the properties of an acrylic denture base resin microwave-polymerised. Journal of Dentistry, 31(7), 463-468. http://dx.doi.org/10.1016/S0300-5712(03)00090-3. PMid:12927457.

15. Blagojevic, V., \& Murphy, V. M. (1999). Microwave polymerization of denture base materials: a comparative study. Journal of Oral Rehabilitation, 26(10), 804-808. http://dx.doi. org/10.1046/j.1365-2842.1999.00456.x. PMid:10564437.

16. Urban, V. M., Machado, A. L., Oliveira, R. V., Vergani, C. E., Pavarina, A. C., \& Cass, Q. B. (2007). Residual monomer of reline acrylic resins: effect of water-bath and microwave post- 
polymerization treatments. Dental Materials, 23(3), 363-368. http://dx.doi.org/10.1016/j.dental.2006.01.021. PMid:16620950.

17. Fortes, C. B. B., Leitune, V. C. B., Collares, F. M., Dornelles, N. B., Jr., Rodrigues, S. B., Samuel, S. W., Petzhold, C. L., \& Stefani, V. (2015). Acrylic resin disinfection by peracetic acid and microwave energy. Revista Gaucha de Odontologia, 63(3), 315318. http://dx.doi.org/10.1590/1981-863720150003000093013.

18. Senna, P. M., Silva, W. J., \& Del Bel Cury, A. A. (2012). Denture disinfection by microwave energy: influence of Candida albicans biofilm. Gerodontology, 29(2), e186-e191. http:// dx.doi.org/10.1111/j.1741-2358.2010.00439.x. PMid:21083738.

19. Consant, R. L. X., Vieira, E. B., Mesquita, M. F., Mendes, W. B., \& Arioli-Filho, J. N. (2008). Effect of microwave disinfection on physical and mechanical properties of acrylic resins. Brazilian Dental Journal, 19(4), 348-353. http://dx.doi. org/10.1590/S0103-64402008000400011. PMid:19180326.

20. Hamouda, I. M., \& Ahmed, S. A. (2010). Effect of microwave disinfection on mechanical properties of denture base acrylic resin. Journal of the Mechanical Behavior of Biomedical Materials, 3(7), 480-487. http://dx.doi.org/10.1016/j.jmbbm.2010.05.002. PMid:20696412.

21. Lombardo, C. E., Canevarolo, S. V., Reis, J. M., Machado, A. L., Pavarina, A. C., Giampaolo, E. T., \& Vergani, C. E. (2012). Effect of microwave irradiation and water storage on the viscoelastic properties of denture base and reline acrylic resins. Journal of the Mechanical Behavior of Biomedical Materials, 5(1), 53-61. http://dx.doi.org/10.1016/j.jmbbm.2011.09.011. PMid:22100079.

22. Ribeiro, D. G., Pavarina, A. C., Machado, A. L., Giampaolo, E. T., \& Vergani, C. E. (2008). Flexural strength and hardness of reline and denture base acrylic resins after different exposure times of microwave disinfection. Quintessence International, 39(10), 833-840. PMid:19093060.

23. Konchada, J., Karthigeyan, S., Ali, S. A., R, V., Amirisetty, R., \& Dani, A. (2013). Effect of simulated microwave disinfection on the mechanical properties of three different types of denture base resins. Journal of Clinical and Diagnostic Research, 7(12), 3051-3053. http://dx.doi.org/10.7860/JCDR/2013/7376.3850. PMid:24551725.

24. Senna, P. M., Da Silva, W. J., Faot, F., \& Del Bel Cury, A. A. (2011). Microwave disinfection: cumulative effect of different power levels on physical properties of denture base resins. Journal of Prosthodontics, 20(8), 606-612. http://dx.doi. org/10.1111/j.1532-849X.2011.00770.x. PMid:21980952.

25. Chassot, A. L., Poisl, M. I., \& Samuel, S. M. (2006). In vivo and in vitro evaluation of the efficacy of a peracetic acid-based disinfectant for decontamination of acrylic resins. Brazilian Dental Journal, 17(2), 117-121. http://dx.doi.org/10.1590/ S0103-64402006000200006. PMid:16924337.

26. Subha, N., Prabhakar, V., Koshy, M., Abinaya, K., Prabu, M., \& Thangavelu, L. (2013). Efficacy of peracetic acid in rapid disinfection of Resilon and gutta-percha cones compared with sodium hypochlorite, chlorhexidine, and povidone-iodine. Journal of Endodontics, 39(10), 1261-1264. http://dx.doi. org/10.1016/j.joen.2013.06.022. PMid:24041388.

27. International. Organization for Standardization - ISO. (1999). ISO 1567: 1999: dentistry-denture base polymers. Geneva: ISO.

28. American Society for Testing and Materials - ASTM. (2010). ASTM D256: standard test methods for determining the izod pendulum impact resistance of plastics. West Conshohocken: ASTM.

29. Shen, C., Javid, N. S., \& Colaizzi, F. A. (1989). The effect of glutaraldehyde base disinfectants on denture base resins. The Journal of Prosthetic Dentistry, 61(5), 583-589. http://dx.doi. org/10.1016/0022-3913(89)90281-3. PMid:2501480.

Received: Apr. 11, 2016

Accepted: Aug. 06, 2016 